\title{
Two novel species of Aspergillus section Nigri from Thai coffee beans
}

Correspondence

Robert A Samson r.samson@cbs.knaw.nl

\section{INTRODUCTION}

Black aspergilli (Aspergillus section Nigri; Gams et al., 1985) are common species in the environment. Although the main habitat of black aspergilli is soil, members of this section have also been isolated from various other sources (Kozakiewicz, 1989). They are not only responsible for food spoilage and biodeterioration, but are also frequently used in biotechnological processes for the production of various enzymes and organic acids. In addition, some black aspergilli have been reported as ochratoxin A-producing

Abbreviations: ITS, internal transcribed spacer region of the rRNA gene cluster; NJ, neighbour-joining; SEM, scanning electron microscopy.

The GenBank/EMBL/DDBJ accession numbers for the $\beta$-tubulin, ITS and calmodulin gene sequences of strains examined in this study are shown in Fig. 1 and Supplementary Figs S1 and S2 (available with the online version of this paper).

The Mycobank (http://www.mycobank.org) accession numbers for $A$. sclerotiicarbonarius sp. nov. and A. aculeatinus sp. nov. are MB 504407 and MB 505075, respectively.

Neighbour-joining phylogenetic trees based on $\beta$-tubulin and ITS gene sequences are available as supplementary figures with the online version of this paper. species in various food commodities (Abarca et al., 1994; Cabañes et al., 2002; Schuster et al., 2002; Abarca et al., 2003; Taniwaki et al., 2003).

During our surveys of the mycobiota of coffee beans from Thailand, black aspergilli were predominant. Several of these isolates were found that differed significantly from the known species assigned to section Nigri. We analysed the relationship of these isolates to other black aspergilli using a polyphasic taxonomic approach. For the phenotypic analyses, macro- and micro-morphology, extrolite production and growth temperatures were studied. For the phylogenetic analyses, calmodulin, $\beta$-tubulin and internal transcribed spacer region of rRNA (ITS) gene sequences were used.

\section{METHODS}

Isolates. The strains used in this study are listed in Table 1 and represent two groups of atypical isolates from Thai coffee beans (Coffea arabica and Coffea canephora var. robusta) and strains from the CBS Fungal Biodiversity Centre (Utrecht, the Netherlands). Other isolates came from the IMI (CABI Bioscience Genetic Resource 
Table 1. Origin and strain numbers for the isolates examined in this study

\begin{tabular}{|c|c|}
\hline Strain number & Origin \\
\hline \multicolumn{2}{|l|}{ A. aculeatinus } \\
\hline CBS $121060^{\mathrm{T}}$ & Arabica coffee, Thailand \\
\hline CBS 121061 & Robusta coffee, Thailand \\
\hline CBS 121062 & Robusta coffee, Thailand \\
\hline CBS 121871 & Robusta coffee, Thailand \\
\hline CBS 121872 & Robusta coffee, Thailand \\
\hline CBS 121873 & Arabica coffee, Thailand \\
\hline CBS 121874 & Arabica coffee, Thailand \\
\hline CBS 121875 & Arabica coffee, Thailand \\
\hline CBS 121876 & Arabica coffee, Thailand \\
\hline CBS 121877 & Arabica coffee, Thailand \\
\hline CBS 115570 & Soil, Japan \\
\hline \multicolumn{2}{|l|}{ 'A. aculeatus' } \\
\hline CBS 114.80 & Soil, India \\
\hline CBS 620.78 (=NRRL 2053) & Unknown \\
\hline A. aculeatus CBS $172.66^{\mathrm{T}}$ & Tropical soil, unknown \\
\hline A. brasiliensis IMI $381727^{\mathrm{T}}$ & Soil, Brazil \\
\hline A. carbonarius CBS $111.26^{\mathrm{T}}\left(=\mathrm{IMI} 16136^{\mathrm{T}}\right)$ & Paper, unknown \\
\hline A. costaricaensis $\mathrm{CBS} 115574^{\mathrm{T}}$ & Soil, Costa Rica \\
\hline A. ellipticus CBS $707.79^{\mathrm{T}}$ (IMI $172283^{\mathrm{T}}$ ) & Soil, Costa Rica \\
\hline \multicolumn{2}{|l|}{ A. foetidus } \\
\hline CBS 564.65 & Unknown, Japan \\
\hline CBS 565.65 & Unknown, Japan \\
\hline A. heteromorphus CBS $117.55^{\mathrm{T}}$ & Culture contaminant, Brazil \\
\hline A. homomorphus CBS $101889^{\mathrm{T}}$ & Soil of Dead Sea, Israel \\
\hline A. ibericus ITEM $4776^{\mathrm{T}}\left(=\mathrm{IMI} 391429^{\mathrm{T}}\right)$ & Grapes, Portugal. \\
\hline A. japonicus CBS $114.51^{\mathrm{T}}$ & Unknown \\
\hline A. lacticoffeatus CBS $101883^{\mathrm{T}}$ & Coffee bean, South Sumatra \\
\hline A. niger CBS $554.65^{\mathrm{T}}\left(=\mathrm{IMI} 050566^{\mathrm{T}}\right)$ & Unknown \\
\hline A. piperis CBS $112811^{\mathrm{T}}$ & Ground black pepper, Denmark \\
\hline \multicolumn{2}{|l|}{ A. sclerotiicarbonarius } \\
\hline CBS 121056 & Robusta coffee, Thailand \\
\hline CBS $121057^{\mathrm{T}}$ & Robusta coffee, Thailand \\
\hline CBS 121851 & Robusta coffee, Thailand \\
\hline CBS 121852 & Robusta coffee, Thailand \\
\hline CBS 121853 & Robusta coffee, Thailand \\
\hline CBS 121854 & Robusta coffee, Thailand \\
\hline A. sclerotioniger CBS $115572^{\mathrm{T}}$ & Green Arabica coffee, India \\
\hline A. tubingensis CBS $134.48^{\mathrm{T}}\left(=\mathrm{IMI} 172283^{\mathrm{T}}\right)$ & Unknown \\
\hline A. uvarum CBS $121591^{\mathrm{T}}$ & Grapes, Brindisi, Italy \\
\hline A. vadensis CBS $113365^{\mathrm{T}}$ & Dead plant tissue, unknown \\
\hline
\end{tabular}

Collection, Egham, England), ITEM (Agri-Food Toxigenic Fungi Culture Collection, Bari, Italy) or IBT collections (BioCentrum-DTU, Kgs. Lyngby, Denmark).

Morphological analysis. For macromorphological observations, Czapek yeast autolysate agar (CYA), malt extract autolysate agar (MEA), yeast extract sucrose agar (YES), creatine agar (CREA), oatmeal agar (OAT) and Czapek agar (CZA) were used (Samson et al., 2004a). The isolates were inoculated at three points on each plate of each medium and incubated at $25{ }^{\circ} \mathrm{C}$ in the dark for 7 days. For micromorphological observations, mounts were made in lactic acid from colonies grown in MEA and a drop of alcohol was added to remove air bubbles and excess conidia. Scanning electron microscopy (SEM) was performed with uncoated frozen samples of conidiophores and conidia on agar plugs with a scanning electron microscope (JEOL 5600LV; JEOL) equipped with an Oxford CT1500 cryostation.

Extrolite analysis. The novel isolates were grown on CYA and YES at $25{ }^{\circ} \mathrm{C}$ for 7 days. Five plugs of each agar medium were taken and pooled into the same vial for extraction with $0.75 \mathrm{ml}$ of a mixture of ethyl acetate/dichloromethane/methanol (3:2:1; by vol.) with $1 \%$ $(\mathrm{v} / \mathrm{v})$ formic acid. The extracts were filtered and analysed by HPLC using alkylphenone retention indices and diode array UV-VIS detection as described by Frisvad \& Thrane (1987), with minor modifications as described by Smedsgaard (1997). The column used was a $50 \times 2 \mathrm{~mm}$ Luna C-18 (II) reversed phase column (Phenomenex) fitted with a $2 \times 2 \mathrm{~mm}$ guard column. Standards from the collection at Biocentrum-DTU for ochratoxin A and B, 
secalonic acid D, neoxaline and other extrolites were used for comparisons with the extrolites detected from the novel isolates.

Phylogenetic analysis. The cultures used for the molecular studies were grown on malt peptone (MP) broth using $10 \%(\mathrm{v} / \mathrm{v})$ malt extract (Brix 10) and $0.1 \%(\mathrm{w} / \mathrm{v})$ bacto peptone (Difco), $2 \mathrm{ml}$ medium in $15 \mathrm{ml}$ tubes. The cultures were incubated at $25{ }^{\circ} \mathrm{C}$ for 7 days. DNA was extracted from the cells using the Masterpure yeast DNA purification kit (Epicentre Biotechnol) according to the manufacturer's instructions. The ITS region of the isolates was amplified using primers ITS1 and ITS4 (White et al., 1990). A fragment of the $5^{\prime}$ portion of the $\beta$-tubulin gene was amplified using the primers bt2a and bt $2 b$ (Glass \& Donaldson, 1995), while a segment of the calmodulin gene was amplified using primers cmd5 and cmd6, as described by Hong et al. (2006). The amplified DNA fragments were purified using a QIAquick PCR purification kit (Qiagene). DNA sequences were determined using a BigDye Terminator v3.1 cycle sequencing kit (ABI) and an ABI 3100 DNA sequencer. Both strands of each fragment were sequenced.

DNA sequences were edited with the DNASTAR computer package and an alignment of the sequences was performed using the CLUSTAL $\mathrm{W}$ program (Thompson et al., 1997). The neighbour-joining (NJ) method was used for the phylogenetic analysis. For NJ analysis, the data were first analysed using the Tamura-Nei parameter distance calculation model with gamma-distributed substitution rates, which were then used to construct the NJ tree with MEGA version 3.1 (Kumar et al., 2004). To determine the support for each clade, a bootstrap analysis was performed with 1000 replications. Aspergillus flavus CBS $100927^{\mathrm{T}}$ was used as outgroup in these analyses.

Phylogenetic analysis of sequence data was also performed using PAUP $4.0 \mathrm{~b} 10$ (Swofford, 2000). Alignment gaps were treated as fifth character state, parsimony uninformative characters were excluded and all characters were unordered and equal weight. Maximumparsimony analysis was performed for all datasets using the heuristic search option. To assess the robustness of the topology, 1000 bootstrap replicates were run by maximum-parsimony (Hillis \& Bull,
1993). Other measures, including tree length, consistency index, retention index (CI and RI, respectively) were also calculated. Sequences were deposited at GenBank under the accession numbers listed in Fig. 1 and Supplementary Figs S1 and S2 (available at IJSEM Online).

\section{RESULTS AND DISCUSSION}

Even though many black species of the genus Aspergillus have been described (Mosseray, 1934; Raper \& Fennell, 1965; Al-Musallam, 1979, Kozakiewicz, 1989; Abarca et al., 2004), and many of these taxa have been reduced to synonymy, eight novel species have been described recently: Aspergillus costaricaensis, Aspergillus lacticoffeatus, Aspergillus piperis and Aspergillus sclerotioniger (Samson et al., 2004b), Aspergillus vadensis (de Vries et al., 2005), Aspergillus ibericus (Serra et al., 2006), Aspergillus brasiliensis (Varga et al., 2007) and Aspergillus uvarum (Samson et al., 2007; Perrone et al., 2008).

In our studies of Thai coffee beans, several black aspergilli were encountered. Aspergillus niger and Aspergillus carbonarius were the dominant species, followed by Aspergillus tubingensis and Aspergillus foetidus. A number of isolates produced conidial heads similar to A. carbonarius, but showed several phenotypical and phylogenetic differences. These isolates, which we propose here as the new taxon Aspergillus sclerotiicarbonarius sp. nov., were found on Robusta green coffee beans collected from the Southern region of Thailand. Based on physiological features, the main differences between A. sclerotiicarbonarius sp. nov. and other species in the Nigri section were detected in CYA at $37{ }^{\circ} \mathrm{C}$ and CREA agar, on which isolates of $A$.

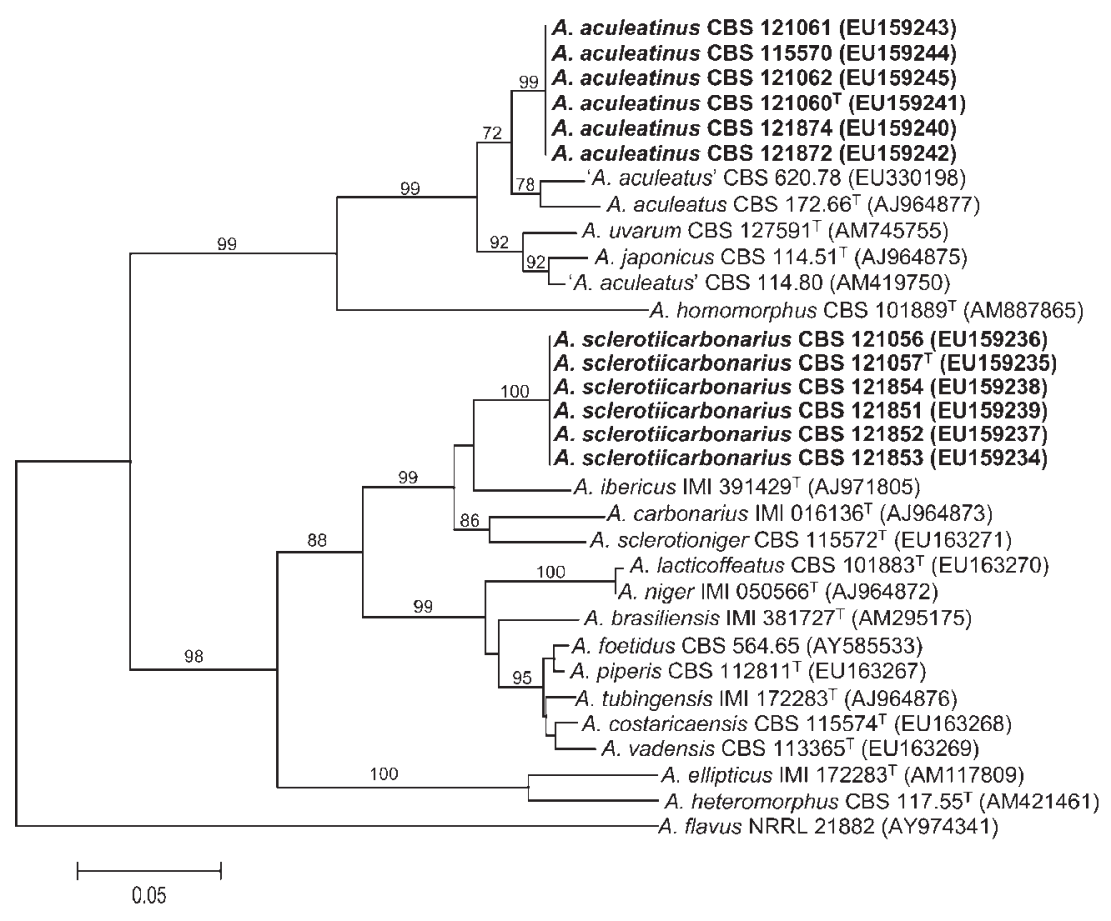

Fig. 1. Neighbour-joining tree based on partial calmodulin gene sequence data for Aspergillus section Nigri. Numbers above the branches are bootstrap values. Only values above $70 \%$ are indicated. Bar, 0.05 substitutions per nucleotide position. 
sclerotiicarbonarius sp. nov. were unable to grow. In contrast, all isolates of the novel species grew very fast on CYA at $25{ }^{\circ} \mathrm{C}$ (CYA25) and YES. As with other species in Aspergillus section Nigri, no growth or germination was detected at $5{ }^{\circ} \mathrm{C}$. There are two phenotypes of Aspergillus sclerotiicarbonarius sp. nov., one with abundant sclerotium production and another producing less sclerotia. Considering the growth pattern of these two phenotypic isolates in MEA at different temperatures, heavily sclerotium-producing isolates stopped growing at a temperature of $33{ }^{\circ} \mathrm{C}$ while the isolates producing less sclerotia stopped growing at a temperature of $36{ }^{\circ} \mathrm{C}$. Isolates of $A$. sclerotiicarbonarius sp. nov. produced similar sclerotia when compared with A. sclerotioniger. The distinguishing characteristic between these two species is the colour of the mycelium; A. sclerotioniger has yellow mycelium, while the mycelium of A. sclerotiicarbonarius is white. A. carbonarius can sometimes produce similar sclerotia, but these two species can be distinguished by the colour of their conidia; the conidia of $A$. carbonarius are carbon black, whereas conidia of A. sclerotiicarbonarius are dark brown. From the SEM and light microscope images (Fig. 2), it is clear that this novel species has conspicuously spiny conidia when young and that verruculose conidia develop at maturity. The conidial ornamentation of $A$. sclerotiicarbonarius is more similar to that of the recently described species, $A$. ibericus (Serra et al., 2006) than to A. carbonarius.

The extrolite analysis showed that isolates of A. sclerotiicarbonarius were able to produce pyranonigrin A, aurasperone B and some unique indol-alkaloids. These were prominent but unknown compounds in the HPLC analysis with retention indices 1475, 1676 and 1838 and were never observed with any other species in the section Nigri. The strains producing more sclerotia produced larger amounts of these indol-alkaloids.

Although two other closely related sclerotium-producing species, A. carbonarius and A. sclerotioniger, are able to produce ochratoxin A (Samson et al., 2004b), this toxin was absent in A. sclerotiicarbonarius. It was suggested by Wicklow et al. (1996) that ochratoxin A was protecting the sclerotia of A. carbonarius from insects, but this hypothesis could not be confirmed for other black aspergilli, since ochratoxin A was not detected in several other sclerotiumproducing species, including A. sclerotiicarbonarius, Aspergillus ellipticus, A. aculeatus, A. costaricaensis, A. brasiliensis and A. piperis (Samson et al., 2004b; Varga et al., 2007).

Another new taxon, which we propose here as Aspergillus aculeatinus sp. nov., was isolated from Arabica coffee beans from the North and Robusta coffee beans from the South of Thailand. It was difficult to differentiate this novel species from other uniseriate species using morphological or physiological characteristics since they could all grow in the temperature range of approximately $9-40{ }^{\circ} \mathrm{C}$. They showed the same growth rate in different media as found for other uniseriate species. However, A. aculeatinus sp. nov. could be distinguished based on the subglobose to ellipsoidal and smaller conidia $(2-5 \mu \mathrm{m})$ compared with $A$. aculeatus/A. japonicus (4-5 $\mu \mathrm{m}$; Fig. 3). Isolates of $A$. aculeatinus sp. nov. consistently produced neoxaline, secalonic acid D and secalonic acid F. Furthermore, strain ATCC 36411 (=CBS 115570) is a known producer of aculeacins (Mizuno et al., 1977; Satoi et al., 1977) and so this antifungal extrolite (Mizoguchi et al., 1977) is also among those that could potentially be produced by $A$. aculeatinus sp. nov. Strains of $A$. aculeatinus sp. nov. also produced a series of extrolites with characteristic retention indices and UV spectra. Even though some of these were unique for A. aculeatinus, their structures have not yet been elucidated.

We examined the genetic relatedness of these isolates to other black aspergilli using sequence analysis of the ITS region of the rRNA gene cluster and parts of the calmodulin and $\beta$-tubulin genes. During analysis of part of the calmodulin gene, 485 characters were analysed. Among the 250 polymorphic sites, 196 were found to be parsimony-informative. The NJ tree based on partial calmodulin genes sequences is shown in Fig. 1. The topology of the tree is the same as one of the more than 416 most parsimonious trees constructed by the PAUP program (length: 627 steps, consistency index: 0.6475, retention index: 0.8637). The $\beta$-tubulin dataset included 405 characters, with 164 parsimony-informative characters. The topology of the NJ (see Supplementary Fig. S1 in IJSEM Online) was the same as that of one of the three most parsimonious trees (tree length: 442, consistency index: 0.6719, retention index: 0.8902). The ITS dataset included 470 characters with 74 parsimony-informative characters. The NJ tree shown in Supplementary Fig. S2 (see IJSEM Online) has the same topology as one of the 156 most parsimonious trees (tree length: 131, consistency index: 0.9160 , retention index: 0.9865$)$.

Based on the phylogenetic analysis of the sequence data for the three loci, isolates of $A$. sclerotiicarbonarius sp. nov. formed a well-supported clade related to A. carbonarius and the related species $A$. sclerotioniger and A. ibericus (Fig. 1, and Supplementary Figs S1 and S2). The isolates of $A$. aculeatinus sp. nov. were found to belong to a clade related to the uniseriate species $A$. uvarum in the tree based on $\beta$-tubulin gene sequence data and to A. uvarum, $A$. aculeatus and $A$. japonicus in the trees based on ITS and calmodulin gene sequence data. Apart from the isolates that were isolated from Thai coffee beans, one isolate that originated from garden soil from Japan was also found to belong to this novel species.

Our Aspergillus species concept is based on a polyphasic approach (Frisvad \& Samson, 2004): A novel species should differ from any other species in diagnostic tests that encompass both phenotypic and phylogenetic features. Here, we have used morphological, physiological and chemotaxonomical features to determine the phenotype and have sequenced three genes in order to characterize the 

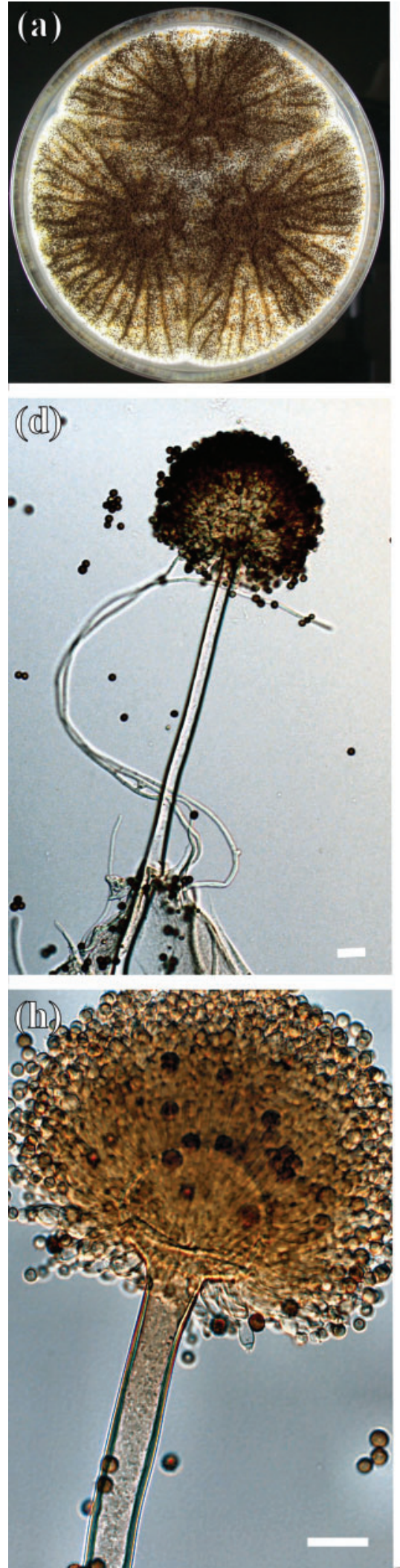
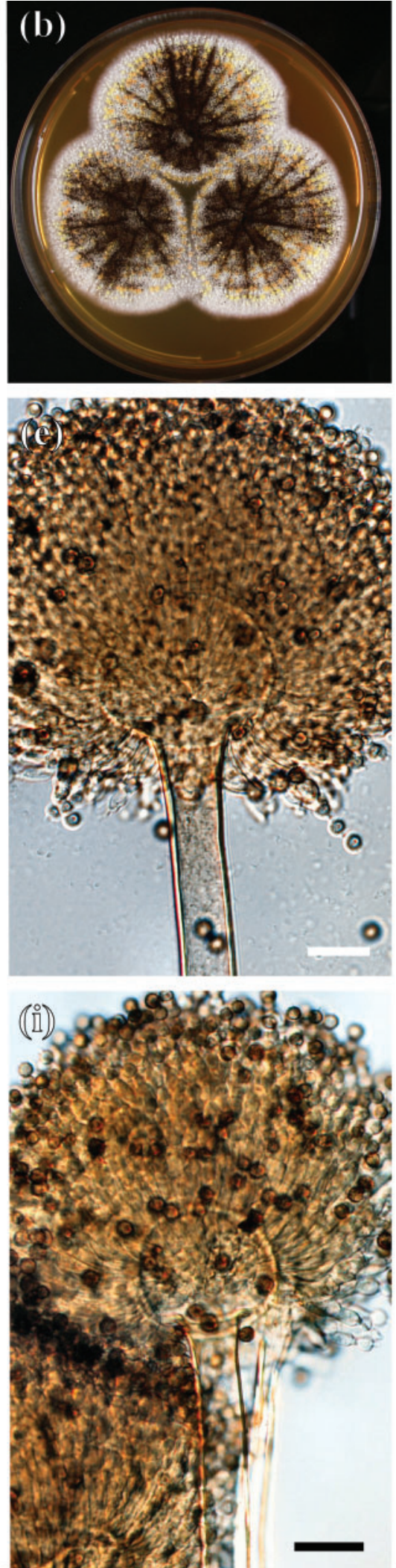
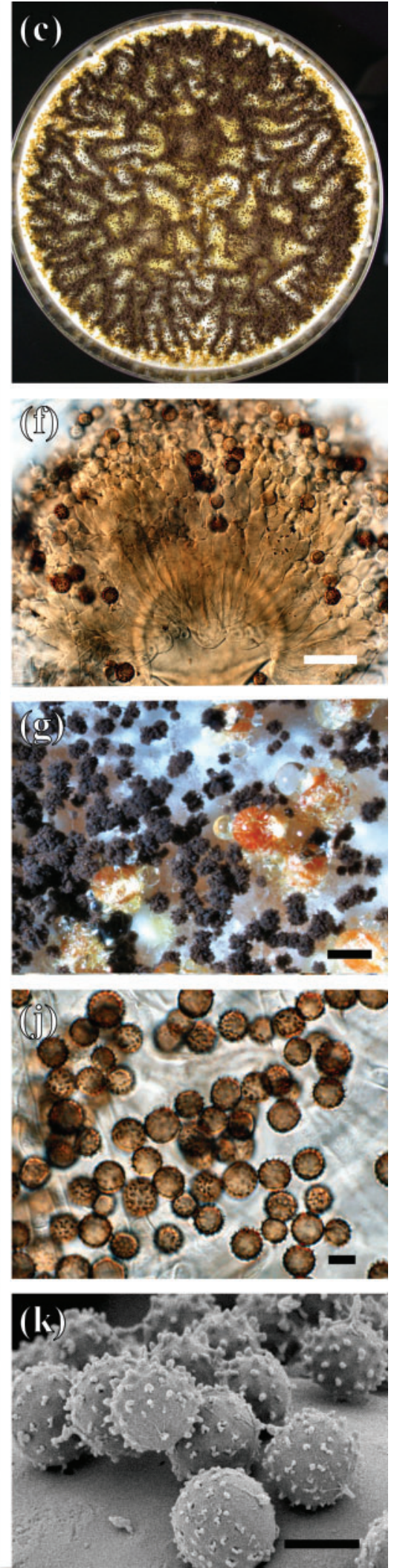

Fig. 2. Aspergillus sclerotiicarbonarius sp. nov. CBS $121057^{\top}$. (a-c) Colonies on (a) CYA, $25{ }^{\circ} \mathrm{C}$; (b) MEA, $25{ }^{\circ} \mathrm{C}$; (c) YES, $25{ }^{\circ} \mathrm{C}$. (d-f, h-i) Conidiophores; (g) sclerotia; (j-k) conidia. Bars, (d-h) $20 \mu \mathrm{m},(\mathrm{i}) 1 \mathrm{~mm},(\mathrm{j}-\mathrm{k}) 5 \mu \mathrm{m}$. 

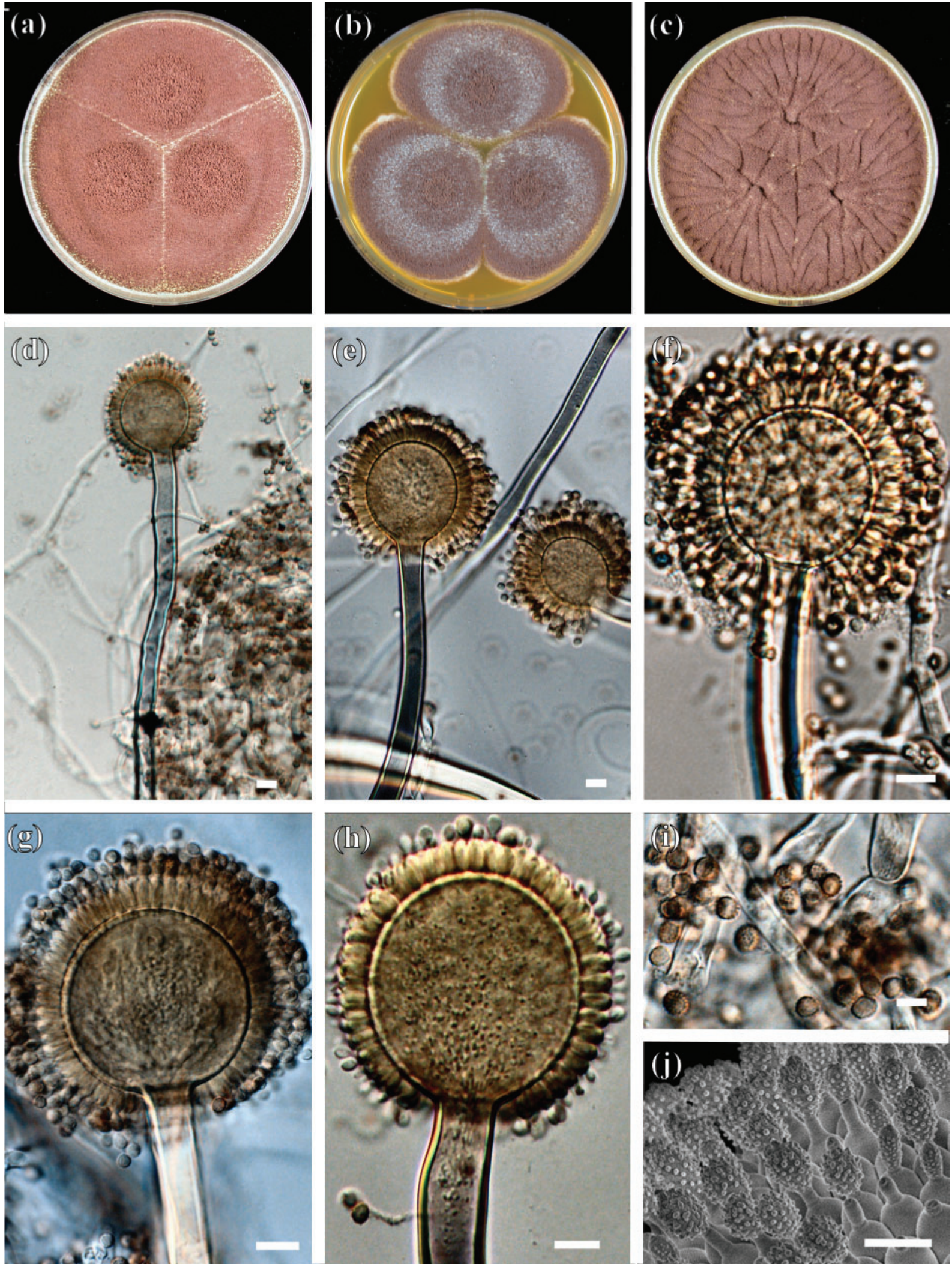

Fig. 3. Aspergillus aculeatinus sp. nov. CBS $121060^{\top}$. (a-c) Colonies on (a) CYA, $25^{\circ} \mathrm{C}$; (b) MEA, $25{ }^{\circ} \mathrm{C}$; (c) YES, $25{ }^{\circ} \mathrm{C}$. (d-h) Conidiophores; (i-j) conidia. Bars, (d-h) $10 \mu \mathrm{m},(i-j) 5 \mu \mathrm{m}$. 
isolates. Because the isolates were unique in their morphology, extrolite profiles and phylogenetic features, we propose two novel species, Aspergillus sclerotiicarbonarius sp. nov. and Aspergillus aculeatinus sp. nov., to accommodate them.

\section{Latin diagnosis of Aspergillus sclerotiicarbonarius Noonim, Frisvad, Varga et Samson sp. nov.}

Aspergillo carbonario similis sed massa conidiorum obscure brunnea et sclerotiis copiosis distinguendus; sclerotia (0.6-) 0.8-1.2 (-1.6) mm, (sub)globose vel ellipsoidea, flava vel aurantia vel rubrobrunnea, hyphis flavis obtecta. Conidia subglobosa, (5.1-) 6-8 (-9.5) × (4.8-) 5.8-7.8 (-8.5) $\mu \mathrm{m}$.

Typus siccus in herb. CBS $121057^{\mathrm{T}}\left(=\mathrm{IBT} 28362^{\mathrm{T}}\right)$, et extypus vivus, isolatus Coffea canephora var. robusta, Chumporn Provincia, Thailand.

\section{Description of Aspergillus sc/erotiicarbonarius Noonim, Frisvad, Varga \& Samson sp. nov. (Fig. 2)}

Aspergillus sclerotiicarbonarius (scler'o.ti.i.car.bon.ar.i.us. N.L. n. sclerotium sclerotium; L. adj. carbonarius of or relating to charcoal, and also a scientific epithet; N.L. masc. adj. sclerotiicarbonarius referring to similarity to Aspergillus carbonarius and the abundant production of sclerotia).

Colony diameters at 7 days at $25{ }^{\circ} \mathrm{C}$ on various agars are: CYA, $85 \mathrm{~mm}$; MEA, 48-64 mm; YES, $>85 \mathrm{~mm}$; CZA, $28-$ 35 , and OAT, $38-52 \mathrm{~mm}$. No growth on CREA or CYA at $37{ }^{\circ} \mathrm{C}$. On CYA25 and MEA, conidiophores are abundantly produced, conidial areas are dark brown; mycelium is white to light yellow; exudates abundantly present, sclerotia abundantly present in most isolates, medium size (minimum 0.6-) 0.8-1.2 (average dimensions) (-1.6 maximum) $\mathrm{mm}$, (sub)globose to ellipsoidal, yellow to orange to red-brown covered by yellow mycelium. On YES agar, white to light yellow hyphae, moderate conidiophores and abundant sclerotia are produced. On OAT, similar to MEA and CYA25, but only few sclerotia are present (at the edge between colonies). On CZA, restricted growth, large irregular shaped yellow-orange sclerotia are produced. Reverse is light yellow on CYA, pinkish yellow and furrowed on MEA, and strikingly bright yellow on YES. Conidial heads radiate, splitting into poorly defined columns with age. Stipes are long (1200-) 1400-2400 $(-2800) \times(13-) \quad 15-23(-27) \mu \mathrm{m}$, walls thick, smooth, hyaline (light yellowish brown pigment on upper portion near conidial head); vesicles (45-) 55-75 (-90) $\mu \mathrm{m}$ wide, pyriform; biseriate; lightly packed metulae covering three quarters of the vesicle, measuring $2-4 \mu \mathrm{m}$ (at base) to 4 $8 \mu \mathrm{m}$ (at top) $\times(28-) 32-39(-45) \mu \mathrm{m}$; phialides $4-7 \times$ 9-14 $\mu \mathrm{m}$; conidia subglobose, (5.1-) 6-8 $(-9.5) \times(4.8-)$ $5.8-7.8(-8.5) \mu \mathrm{m}$, conspicuously spiny when young, becoming verruculose when mature. Extrolites comprise pyranonigrin $\mathrm{A}$, aurasperone $\mathrm{B}$ and three unique indolalkaloids at retention indices 1475, 1676 and 1838. The distinguishing features of this species are its inability to grow in CREA and on CYA at $37{ }^{\circ} \mathrm{C}$, the rough (wrinkled) colony surface, heavily sclerotia production and the strikingly bright yellow reverse of the colony in YES. A. sclerotiicarbonarius isolates grow well at $25^{\circ} \mathrm{C}$, but not at $37{ }^{\circ} \mathrm{C}$.

The type strain, CBS $121057^{\mathrm{T}}\left(=\mathrm{IBT} 28362^{\mathrm{T}}\right)$, was isolated from surface-disinfected Coffea canephora var. robusta dried coffee cherries and green coffee beans from the Sawi District, Chumporn Province, Thailand. The Mycobank accession number is MB 504407.

\section{Latin diagnosis of Aspergillus aculeatinus Noonim, Frisvad, Varga et Samson sp. nov.}

Aspergillo aculeato similimus, sed conidiis paulo minoribus distinguendus; conidia subglobose vel ellipsoidea, 2-4 × 2.3$4.4 \mu \mathrm{m}$, echinulata.

Typus siccus in herb. CBS $121060^{\mathrm{T}}\left(=\mathrm{IBT} 29077^{\mathrm{T}}\right)$, et extypus vivus, isolatus Coffea arabica, Chiangmai Provincia, Thailand.

\section{Description of Aspergillus aculeatinus Noonim, Frisvad, Varga \& Samson sp. nov. (Fig. 3)}

Aspergillus aculeatinus (a.cul.e.a.ti.nus. L. adj. aculeatus furnished with stings or prickles, thorny, prickly, and also a scientific epithet; L. suff. -inus - $a$-um adjectival suffix used with the sense of belonging to; N.L. masc. adj. aculeatinus similar to Aspergillus aculeatus).

Colony diameters at 7 days and $25{ }^{\circ} \mathrm{C}$ on the following agars: CYA, $>85 \mathrm{~mm}$; MEA, $78-85 \mathrm{~mm}$; YES, $>85 \mathrm{~mm}$; CZA, 33-43; OAT, 55-64 mm, and CREA, 13-52 mm. Colony diameter on CYA at $37^{\circ} \mathrm{C}$ is $22-33 \mathrm{~mm}$. On CYA and MEA, conidiophores are produced abundantly, conidial areas are light brown; sclerotia are present in some isolates but no sclerotia are observed in culture ex type, small (0.4-0.6), globose to subglobose, creamish to light yellow. Reverse of the colony is light yellow on CYA agar, light brown and furrowed on MEA and bright yellow on YES. Conidial heads radiate, splitting into poorly defined columns or 2-6 well-defined columns with age; stipes are short (minimum 380-) 500-620 (average dimensions) $(-800$ maximum $) \times(9-) \quad 11-14(-16) \mu \mathrm{m}$, walls thin, smooth, hyaline; vesicles (43-) 55-65 $(-82) \mu \mathrm{m}$ wide, globose; uniseriate; phialides flask-shaped and cover the entire surface of the vesicle, measuring 1.8-3.5 $\times 6.1-$ $9.0 \mu \mathrm{m}$; conidia subglobose to ellipsoidal, $2-4 \times 2.3-$ $4.4 \mu \mathrm{m}$, echinulate. Strains of this species produce neoxaline, secalonic acid $\mathrm{D}$, secalonic acid $\mathrm{F}$ and aculeacins. Distinguishing features of this species are small $(2-5 \mu \mathrm{m})$ subglobose to ellipsoidal conidia and the production of unique extrolites (neoxaline, aculeacins, secalonic acid D and secalonic acid F)

The type strain, CBS $121060^{\mathrm{T}}\left(=\mathrm{IBT} 29077^{\mathrm{T}}\right)$, was isolated from Coffea arabica (dried parchment and green coffee 
beans), Muang District, Chiangmai Province, Thailand. The Mycobank accession number is MB 505075.

\section{ACKNOWLEDGEMENTS}

The authors gratefully thank the Commission on Higher Education, the Ministry of Education and Graduate School, Kasetsart University, Thailand for financial support for the research. We also thank Dr Jan Dijksterhuis for taking SEM pictures and Dr Walter Gams for kindly preparing the Latin diagnoses.

\section{REFERENCES}

Abarca, M. L., Bragulat, M. R., Castellá, G. \& Cabañes, F. J. (1994). Ochratoxin A production by strains of Aspergillus niger var. niger. Appl Environ Microbiol 60, 2650-2652.

Abarca, M. L., Accensi, F., Bragulat, M. R., Castellá, G. \& Cabañes, F. J. (2003). Aspergillus carbonarius as the main source of ochratoxin A contamination in dried vine fruits from the Spanish market. J Food Prot 66, 504-506.

Abarca, M. L., Accensi, F., Cano, J. \& Cabañes, F. J. (2004). Taxonomy and significance of black aspergilli. Antonie van Leeuwenhoek 86, 33-49.

Al-Musallam, A. (1979). Revision of the Black Aspergillus Species. Baarn: Centraalbureau voor Schimmelcultures.

Cabañes, F. J., Accensi, F., Bragulat, M. R., Abarca, M. L., Castellá, G., Minguez, S. \& Pons, A. (2002). What is the source of ochratoxin A in wine? Int J Food Microbiol 79, 213-215.

de Vries, R. P., Frisvad, J. C., van de Vondervoort, P. J. I., Burgers, K., Kuijpers, A. F. A., Samson, R. A. \& Visser, J. (2005). Aspergillus vadensis, a new species of the group of black Aspergilli. Antonie van Leeuwenhoek 87, 195-203.

Frisvad, J. C. \& Thrane, U. (1987). Standardized high-performance liquid chromatography of 182 mycotoxins and other fungal metabolites based on alkylphenone retention indices and UV-VIS spectra (diode-array detection). J Chromatogr 404, 195-214.

Frisvad, J. C. \& Samson, R. A. (2004). Polyphasic taxonomy of Penicillium subgenus Penicillium. A guide to identification of food and air-borne terverticillate Penicillia and their mycotoxins. Stud Mycol 49, 1-173.

Gams, W., Christensen, M., Onions, A. H. S., Pitt, J. I. \& Samson, R. A. (1985). Infrageneric taxa of Aspergillus. In Advances in Penicillium and Aspergillus Systematics, pp. 55-61. Edited by R. A. Samson \& J. I. Pitt. New York: Plenum Press.

Glass, N. L. \& Donaldson, G. C. (1995). Development of primer sets designed for use with the PCR to amplify conserved genes from filamentous Ascomycetes. Appl Environ Microbiol 61, 1323-1330.

Hillis, D. M. \& Bull, J. J. (1993). An empirical test of bootstrapping as a method for assessing confidence in phylogenetic analysis. Syst Biol 42, 182-192.

Hong, S. B., Cho, H. S., Shin, H. D., Frisvad, J. C. \& Samson, R. A. (2006). Novel Neosartorya species isolated from soil in Korea. Int J Syst Evol Microbiol 56, 477-486.

Kozakiewicz, Z. (1989). Aspergillus species on stored products. Mycol Pap 161, 1-188.

Kumar, S., Tamura, K. \& Nei, M. (2004). MEGA3: integrated software for molecular evolutionary genetics analysis and sequence alignment. Brief Bioinform 5, 150-163.
Mizoguchi, J., Saito, T., Mizuno, K. \& Hayano, K. (1977). On the mode of action of a new antifungal antibiotic, aculeacin A: inhibition of cell-wall synthesis in Saccharomyces cerevisiae. J Antibiot (Tokyo) 30, 308-313.

Mizuno, K., Yagi, A., Satoi, S., Takada, M., Hayashi, M., Asano, K. \& Matsuda, T. (1977). Studies on aculeacin. I. Isolation and characterization of aculeacin A. J. Antibiot (Tokyo) 30, 297-302.

Mosseray, R. (1934). Les Aspergillus de la section "Niger" Thom et Church. Cellule 43, 203-285.

Perrone, G., Varga, J., Susca, A., Frisvad, J. C., Stea, G., Kocsube, S., Toth, B., Kozakiewicz, Z. \& Samson, R. A. (2008). Aspergillus uvarum sp. nov., an uniseriate black Aspergillus species isolated from grapes in Europe. Int J Syst Evol Microbiol 58, 1032-1039.

Raper, K. B. \& Fennell, D. I. (1965). The Genus Aspergillus. Baltimore: Williams \& Wilkins.

Samson, R. A., Hoekstra, E. S. \& Frisvad, J. C. (2004a). Introduction to Food- and Airborne Fungi, 7th edn. Utrecht, The Netherlands: Centraalbureau voor Schimmelcultures.

Samson, R. A., Houbraken, J. A. M. P., Kuijpers, A. F. A., Frank, J. M. \& Frisvad, J. C. (2004b). New ochratoxin A or sclerotium producing species in Aspergillus section Nigri. Stud Mycol 50, 45-61.

Samson, R. A., Noonim, P., Meijer, M., Houbraken, J., Frisvad, J. C. \& Varga, J. (2007). Diagnostic tools to identify black aspergilli. Stud Mycol 59, 129-145.

Satoi, S., Yagi, A., Asano, K., Mizuno, K. \& Watanabe, T. (1977). Studies on aculeacin. II. Isolation and characterization of aculeacins B, C, D, E, F and G. J Antibiot (Tokyo) 30, 303-307.

Schuster, E., Dunn-Coleman, N., Frisvad, J. C. \& van Dijck, P. W. M. (2002). On the safety of Aspergillus niger - a review. Appl Microbiol Biotechnol 59, 426-435.

Serra, R., Cabañes, F. J., Perrone, G., Castella, G., Venancio, A., Mule, G. \& Kozakiewicz, Z. (2006). Aspergillus ibericus: a new species of section Nigri isolated from grapes. Mycologia 98, 295-306.

Smedsgaard, J. (1997). Micro-scale extraction procedure for standardized screening of fungal metabolite production in cultures. J Chromatogr A 760, 264-270.

Swofford, D. L. (2000). PAUP* 4.0: phylogenetic analysis using parsimony. Sunderland, MA: Sinauer Associates.

Taniwaki, M. H., Pitt, J. I., Teixeira, A. A. \& lamanaka, B. T. (2003). The source of ochratoxin A in Brazilian coffee and its formation in relation to processing methods. Int J Food Microbiol 82, 173-179.

Thompson, J. D., Gibson, T. J., Plewniak, F., Jeanmougin, F. \& Higgins, D. G. (1997). The CLUSTAL_X windows interface: flexible strategies for multiple sequence alignment aided by quality analysis tools. Nucleic Acids Res 25, 4876-4882.

Varga, J., Kocsubé, S., Tóth, B., Frisvad, J. C., Perrone, G., Susca, A., Meijer, M. \& Samson, R. A. (2007). Aspergillus brasiliensis sp. nov., a biseriate black Aspergillus species with world-wide distribution. Int $J$ Syst Evol Microbiol 57, 1925-1932.

White, T. J., Bruns, T., Lee, S. \& Taylor, J. (1990). Amplification and direct sequencing of fungal ribosomal RNA genes for phylogenetics. In PCR Protocols: A Guide to Methods and Applications, pp. 315-322. Edited by M. A. Innis, D. H. Gelfand, J. J. Sninsky \& T. J. White. San Diego: Academic Press.

Wicklow, D. T., Dowd, P. F., Alfatafta, A. A. \& Gloer, J. B. (1996). Ochratoxin A: an antiinsectan metabolite from the sclerotia of Aspergillus carbonarius NRRL 369. Can J Microbiol 42, 1100-1103. 